ORIGINAL ARTICLE

\title{
Outcome of Laminoplasty in Patients with Multilevel Cervical Myelopathy
}

\author{
FAIQ SHEIKH, ${ }^{1}$ FAHEEM AHMAD USMANI, ${ }^{1}$ ADNAN KHALID ${ }^{1}$ \\ TARIQ SALAHUDDIN, ${ }^{2}$ JAMAL NASIR ${ }^{3}$ \\ ${ }^{1}$ Department of Neurosurgery Unit-I, Punjab Institute of Neurosciences (PINS), Lahore General \\ Hospital (LGH), ${ }^{2}$ National Hospital \& Medical Care, ${ }^{3}$ Children Hospital, Lahore - Pakistan \\ DOI: https://doi.org/10.36552/pjns.v23i3.361
}

\begin{abstract}
Objective: To determine the outcome of surgical intervention in the form of laminoplasty in the patients with multilevel cervical myelopathy.

Material and Methods: Descriptive case series, was conducted at NS-I, PINS, Lahore for 6 months. The patients were included through non probability consecutive sampling that fulfilled inclusion criteria. All of the patients were assessed using JOA score before and after 2 months of surgery. General characteristics, including age, gender, other medical conditions and other risk factors were assessed prior to surgery. The total number of 35 patients was included with expected JOA percentage recovery rate of $75 \%+21 \%$ after the procedure.

Results: In this study 35 total patients were enrolled. The mean age was $55.68+9.92$ years. Total number of male patients were 23 (65.71), while the female was 12 (34.29). The mean duration of degenerative cervical myelopathy was $3.90+1.3$ months. The mean pre op value of JOA score was $7.08+2.7(4-10)$ for the patients. The mean post op score was $13.00+2.30(9-17)$. The mean recovery value calculated at two month interval was $62.12+17.39(38.46-100)$. Statistically, there was a significant difference of outcome of pre and post op value of JOA scores i.e., $p$ value $=0.00$.

Conclusion: Our study determined that, the open door laminoplasty is an effective and reliable technique with good outcome in the treatment of multi-level degenerative cervical spine myelopathy patients.
\end{abstract}

Key Words: Myelopathy, Laminoplasty, degenerative cervical spine, JOA score, Recovery.

\section{INTRODUCTION}

The cervical myelopathy is due toabnormality in the spinal cord that disrupts or interrupts the normal transmission of neural signal in the neck region. ${ }^{1}$ Cervical laminoplasty is an alternative surgical intervention to traditional cervical laminectomy and fusion and multilevel corpectomy or cervical spondylosis myelopathy. So we conducted this study to find out the efficiency of open laminoplasty. According to the number of studies Cervical degenerative myelopathy is a disorder effecting $2 \%$ of patients seeking neurosurgical consideration. Main causes of trauma or infection, auto immune or inflammatory disorders, tumors or degenerative processes including spondylosis, PIVD and OPLL. ${ }^{2}$
Patients may present with a variety of symptoms and many of these are non-specific. The classical presentation is loss of balance, poor coordination, weakness, numbness and in severe cases paralysis. Pain, sphincterdysfunction can also be present ${ }^{3}$. CM is a progressive disease requiring surgical intervention. Opinions included are anterior and posterior approaches when indicated surgery should be performed within six months or 1 year after commencement of symptoms for better outcome ${ }^{3}$. There is a disagreement regarding to which technique is best for multilevel posterior cervical decompression, the traditional being laminectomy with and without fusion. ${ }^{4}{ }^{5}$ Cervical laminoplasty becomes a feasible posterior decompression technique for cervical spinal 
cord as an effort to treat multi segmental cord compression. ${ }^{6}$

The incentive of this technique was to decompress long segments while preventing posterior laminectomy, membrane formation and Kyphosis. Different approaches include open door, the midline French window and $\mathrm{Z}$ plasty. Each of these techniques presents widening of canal while providing posterior laminal cover. Questions regarding laminoplasty include its efficacy in improving symptoms, outcome compared with other techniques and its complications. $^{7}$ The outcome of open door laminoplasty is measured using JOA score

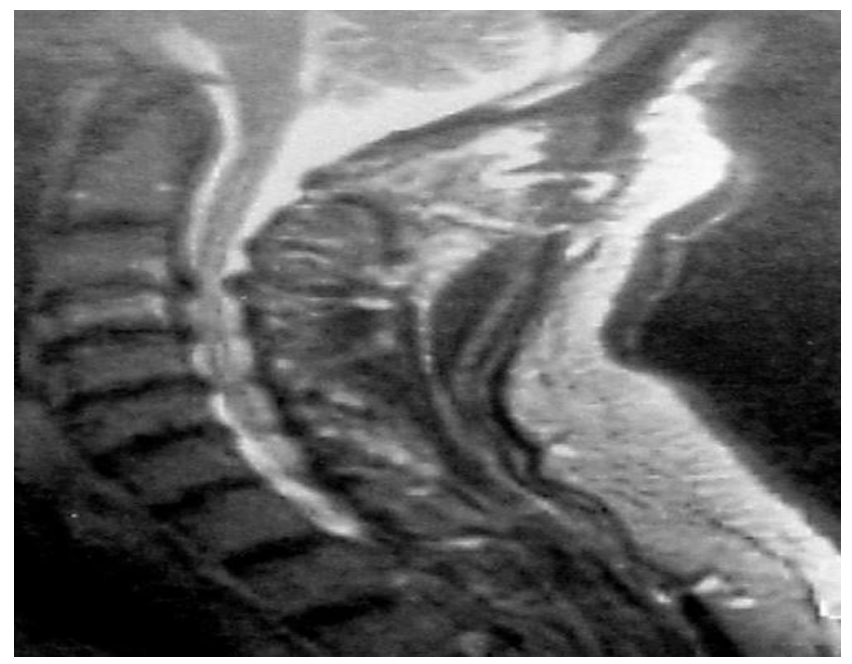

Fig. 1: MRI sagittal section of a patient with multilevel cervical myelopathy.

\section{MATERIALS \& METHODS}

\section{Study Design}

Descriptive case series, was conducted at NS-I, PINS, Lahore for 6 months.

Table 1: The distribution of patients based on duration of symptoms, pre-operative, post-operative JOA score and their significance.

\begin{tabular}{|l|l|l|l|l|}
\hline \multicolumn{2}{|l|}{ Study variable } & Mean \pm S.D & Range & p-value \\
\hline \multirow{2}{*}{$\begin{array}{l}\text { Duration of } \\
\text { Symptoms }\end{array}$} & Male & $3.90 \pm 1.13$ & $3.00-5.00$ & \multirow{2}{*}{0.561} \\
\cline { 2 - 4 } & Female & $4.2 \pm 1.9$ & $4.00-6.00$ & \\
\hline \multirow{2}{*}{ JOA Score } & Pre & $7.08 \pm 2.07$ & $4-10$ & \multirow{2}{*}{$<0.001^{*}$} \\
\cline { 2 - 4 } & Post & $13 \pm 2.30$ & $9-17$ & \\
\hline
\end{tabular}

*t-test, p-value significant at 0.01 level of significance

\section{Inclusion Criteria}

The patients were included through non probability consecutive sampling that fulfilled inclusion criteria. All of the patients were assessed using JOA score before and after 2 months of surgery. General characteristics, including age, gender, other medical conditions, and other risk factors were assessed prior to surgery. The total number of 35 patients was included with expected JOA percentage recovery rate of $75 \%+21 \%$ after the procedure. Both male and female Aged between 40 - 70 years, having a degenerative spine disease for more than 6 months was selected in the study.

\section{Exclusion Criteria}

Whereas patients having severe co morbidities and with kyphotic cervical spine deformity were concluded from the study.

\section{Peri, Intra and Post-Operative Care}

Informed consent prior to surgery was taken from the patient or their close family member. Pre operatively all anti-coagulants were withheld. All the perioperative procedures were standardized. ${ }^{8}$ Allpf the procedures were carried out under GA. The lamina of the involved level was drilled on one side, opposite side acting as a hinge and was fixed with micro plates and screws. Post op hard cervical collar was applied. The post op JOA score was assessed at 2 months interval.

\section{Statistical Analysis}

The data was analyzed using SPSS for Windows version 20.0. All variables were expressed as means + standard deviation (X+SD). The investigated parameters were analyzed with $t$ test and chi square test. $\mathrm{P}$ value of 0.05 was considered significant.

\section{RESULTS}

In this study, 35 total patients were enrolled. The mean age was $55.68+9.92$ years. $23(65.71 \%)$ patients were male, while female were 12 (34.29\%). The mean duration of degenerative cervical myelopathy was $3.90+1.3$ months. The mean pre op value of JOA score was 7.08 $+2.7(4-10)$ for the patients. The mean 
Table 2: Statistics of age (years).

\begin{tabular}{|l|l|c|}
\hline \multirow{4}{*}{ Age (years) } & $\mathbf{n}$ & 35 \\
\cline { 2 - 3 } & Mean & 55.68 \\
\cline { 2 - 3 } & SD & 9.92 \\
\cline { 2 - 3 } & Minimum & 40.00 \\
\cline { 2 - 3 } & Maximum & 70.00 \\
\hline
\end{tabular}

Table 3: Distribution of Symptoms in Male Patients.

\begin{tabular}{|l|l|c|}
\hline \multirow{4}{*}{$\begin{array}{l}\text { Duration of Symptoms } \\
\text { (Months) }\end{array}$} & $\mathbf{n}$ & 23 \\
\cline { 2 - 3 } & Mean & 3.90 \\
\cline { 2 - 3 } & $\mathrm{SD}$ & 1.13 \\
\cline { 2 - 3 } & Minimum & 3.00 \\
\cline { 2 - 3 } & Maximum & 5.00 \\
\hline
\end{tabular}

Table 4: Distribution of Symptoms in Female Patients.

\begin{tabular}{|l|l|c|}
\hline \multirow{4}{*}{$\begin{array}{l}\text { Duration of Symptoms } \\
\text { (Months) }\end{array}$} & $\mathbf{n}$ & 12 \\
\cline { 2 - 3 } & Mean & 4.2 \\
\cline { 2 - 3 } & SD & 1.9 \\
\cline { 2 - 3 } & Minimum & 4.00 \\
\cline { 2 - 3 } & Maximum & 6.00 \\
\hline
\end{tabular}

Table 5: Pre-op JOA score.

\begin{tabular}{|l|l|c|}
\hline \multirow{4}{*}{ Pre-op JOA score } & $\mathbf{n}$ & 35 \\
\cline { 2 - 3 } & Mean & 7.08 \\
\cline { 2 - 3 } & SD & 2.07 \\
\cline { 2 - 3 } & Minimum & 4.00 \\
\cline { 2 - 3 } & Maximum & 10.00 \\
\hline
\end{tabular}

Table 6: Post-op JOA score.

\begin{tabular}{|l|l|r|}
\hline \multirow{4}{*}{ Post-op JOA score } & $\mathbf{n}$ & 35 \\
\cline { 2 - 3 } & Mean & 13.00 \\
\cline { 2 - 3 } & SD & 2.30 \\
\cline { 2 - 3 } & Minimum & 9.00 \\
\cline { 2 - 3 } & Maximum & 17.00 \\
\hline
\end{tabular}

Table 7: Comparison of pre and post-operative JOA score.

\begin{tabular}{|l|l|c|c|}
\hline \multicolumn{2}{|c|}{} & Pre-op & Post-op \\
\hline \multirow{3}{*}{ JOA score } & $\mathrm{n}$ & 35 & 35 \\
\cline { 2 - 4 } & Mean & 7.08 & 13.00 \\
\cline { 2 - 4 } & SD & 2.07 & 2.30 \\
\hline
\end{tabular}

Paired t-test $=-5.91$ with $\mathrm{p}$-value $=0.000$ (Significant $)$

Table 8: Descriptive statistics of recovery.

\begin{tabular}{|l|l|c|}
\hline \multirow{4}{*}{ Recovery } & $\mathbf{N}$ & 35 \\
\cline { 2 - 3 } & Mean & 62.12 \\
\cline { 2 - 3 } & SD & 17.39 \\
\cline { 2 - 3 } & Minimum & 38.46 \\
\cline { 2 - 3 } & Maximum & 100.00 \\
\hline
\end{tabular}

post op score was $13.00+2.30(9-17)$. The mean recovery value calculated at two months interval was $62.12+17.39$ (38.46 - 100). Statistically, there was a significant difference of outcome of pre and post op value of JOA scores, i.e. ( $\mathrm{p}$ value $<0.001$ ).

\section{DISCUSSION}

This present descriptive case series study was conducted at the Department of Neurosurgery, PGMI/ Lahore General Hospital, Lahore to assess the mean recovery rate of open door laminoplasty in patients having multi-level degenerative cervical myelopathy. Laminoplasty is an outstanding technique in lordotic spines, in younger patients, where fusion is unattractive and who can retain at least restricted cervical spine mobility post operatively. There are two main types, the French door and the open door.This procedure was invented by Japanese orthopedic surgeons because of high rates of ossification of posterior longitudinal ligament in the region.

Cervical myelopathy is a disorder affecting $2 \%$ of patients seeking neurosurgical consultation.In our study, the mean recovery value of the patients was $62.12 \pm 17.39$. The mean pre-op value of JOA score was $7.08 \pm 2.07$ while the mean post-op value of the JOA score of the patients was $13.00 \pm 2.30$. Statistically significant difference was discovered between the pre and post-op values of JOA scores. i.e., 
p-value $=0.000$. Some of the studies are discussed below which are in support of our study findings and a few are in contrary. Eiren et al. resulted in their study that the open-door technique produced acceptable postoperative outcomes on the basis of clinical and radiological findings for both CSM and OPLL.

The outcome of open door laminoplasty was measured by means of the Japanese orthopedic association score. Various studies have reported a recovery rate of around $50-70 \%$. The mean JOA recovery rate was $75 \%+/-21.1 \% .^{12}$ One study showed that the Laminoplasty with mini-plates has been revealed to be a trustworthy technique in multi segment pathology. However, the outcome is inferior in patients over 75 years of age. Aluizio et al. ${ }^{2}$ had concluded in their study that two-doors laminoplasty technique has better outcome and can used as alternative modality for stable multi segmental cervical spondylotic myelopathy.

Different studies have shown the betterment of JOA score was about $60 \%$, the lordosis angle followedofx-ray cervical spine lateral view was preserved, and range of motion reduced in cervical myelopathy as well as in an ossified posterior longitudinal ligament.On contrary a study by Chusheng et al. revealed that the posterior approach is less time taking and better improvement in JOA scores 6 months postoperatively. The anterior surgery group had better improvement of NDI scores 6 months postoperatively and less blood loss intraoperatively. The differencein JOA scores, JOA recovery rates for anterior and posterior approach was not statistically significant.

In one study general recovery varies from $50 \%$ to $70 \%$. The preoperative clinical status determines the surgical outcome not the surgical technique.A review research regarding the efficacy of laminectomy and fusion versus laminoplasty for the treatment of multilevel cervical spondylotic myelopathy revealed that the laminoplasty is superior to surgical treatment. Complications like nerve palsy were higher in laminectomy and fusion. ${ }^{9}$

Xin et al. demonstrated in their study that JOA score increased from 8.5 per operative to 13.43 postoperative with a recovery rate of $58.2 \%$ ( $\mathrm{p}$ value $<0.05) .{ }^{10}$ They concluded that laminoplasty is simple and effective method for cervical decompression and neurological recovery. The laminoplasty with miniplate instrumentation is trustworthy technique in multi-segment pathology, ${ }^{11}$ However, outcome is inferior in patients over 75 years of age. ${ }^{12}$
The two open door laminoplasty procedure is safer, easier to perform and efficientsubstitute for stable multi segment cervical sondylyticmyelopathy. The JOA score improvement was about $60 \%$, the lordotic angle was preserved in both CSM and OPLL groups. ${ }^{13}$

\section{CONCLUSION}

The open door laminoplasty is an effective and reliable procedure with good outcome in the management of multilevel degenerative cervical spine myelopathy patients.

\section{Additional Information}

Disclosures: Authors report no conflict of interest.

Human Subjects: Consent was obtained by all patients/ participants in this study.

\section{Conflicts of Interest:}

In compliance with the ICMJE uniform disclosure form, all authors declare the following:

Financial Relationships: All authors have declared that they have no financial relationships at present or within the previous three years with any organizations that might have an interest in the submitted work.

Other Relationships: All authors have declared that there are no other relationships or activities that could appear to have influenced the submitted work.

\section{Address for Correspondence: Dr. Jamal Nasir Department of Neurosurgery, Children Hospital, Lahore - Pakistan Email:jamal.wahgra@gmail.com}

\section{REFERENCES}

1. Paul C. McCormick, Michael G. Kaiser, Peter D. Angevine, Alfred T. Ogden, Mandigo CE, Reid PC. Cervical Spondylotic Myelopathy. 2019. https://www.columbiaspine.org/condition/cervicalspondylotic-myelopathy/2019).

2. Arantes Júnior AA, Silva Junior GAd, Malheiros JA, et al. A new expansive two-open-doors laminoplasty for multilevel cervical spondylotic myelopathy: technical report and follow-up results. Arquivos de neuropsiquiatria. 2014; 72 (1): 49-54.

3. NHS. Cervical spondylosis. 2017. https://www.nhs.uk/conditions/cervical-spondylosis/.

4. Lao L, Zhong G, Li X, Qian L, Liu Z. Laminoplasty versus laminectomy for multi-level cervical spondylotic myelopathy: a systematic review of the literature. 
Journal of orthopaedic surgery and research, 2013; 8 (1): 45 .

5. Shunzhi Y, Zhonghai L, Fengning L, Zhi C, Tiesheng H. Surgical management of 4-level cervical spondylotic myelopathy. Orthopedics, 2013; 36 (5): e613-e20.

6. Oe K, Doita M, Miyamoto H, Kanda F, Kurosaka M, Sumi M. Is extensive cervical laminoplasty an effective treatment for spinal cord sarcoidosis combined with cervical spondylosis? European Spine Journal, 2009; 18 (4): 570-6.

7. Matz PG, Anderson PA, Groff MW, et al. Cervical laminoplasty for the treatment of cervical degenerative myelopathy. Journal of Neurosurgery: Spine, 2009; 11 (2): 157-69.

8. Singh K, Vaccaro AR. Pocket atlas of spine surgery: Thieme; 2018.

9. Yuan X, Wei C, Xu W, Gan X, Cao S, Luo J. Comparison of laminectomy and fusion vs laminoplasty in the treatment of multilevel cervical spondylotic myelopathy: A meta-analysis. Medicine, 2019; 98 (13).
10. Li X-K, Liu X, Che L, Ma C-J, Samartzis D, Wang HQ. Cervical open-door laminoplasty technique with simple sutures and bone grafts: a single institutional study with 30 consecutive cases. Journal of orthopaedic surgery and research, 2015; 10 (1): 14.

11. Bratcher K, Brock D, Glassman SD, Campbell MJ, Carreon LY. Instrumented open-door laminoplasty as treatment for cervical myelopathy in 104 patients. American journal of orthopedics (Belle Mead, NJ) 2009; 38 (7): E123-8.

12. Oki S, Matsuda Y, Shibata T, Okumura H, Desaki J. Morphologic differences of the vascular buds in the vertebral endplate: scanning electron microscopic study. Spine, 1996; 21 (2): 174-7.

13. Tanaka N, Nakanishi K, Fujimoto Y, et al. Expansive laminoplasty for cervical myelopathy with interconnected porous calcium hydroxyapatite ceramic spacers: comparison with autogenous bone spacers. Clinical Spine Surgery, 2008; 21 (8): 547-52.

\begin{tabular}{|c|c|c|c|}
\hline \multicolumn{4}{|c|}{ AUTHORSHIP AND CONTRIBUTION DECLARATION } \\
\hline Sr.\# & Author's Full Name & Intellectual/Contribution to Paper in Terms of: & \multirow{3}{*}{$\begin{array}{l}\text { Signature by the } \\
\text { author(s) } \\
\text { Faiq }\end{array}$} \\
\hline 1. & $\begin{array}{l}\text { Faiq Sheikh } \\
\text { (Main/Principal Author). }\end{array}$ & \multirow{5}{*}{$\begin{array}{l}\text { 2. Data collection and calculations } \\
\text { 3. Analysis of data and interpretation of results etc. } \\
\text { 4. Literature review, manuscript writing and } \\
\text { quality insurer } \\
\text { 5. Paper writing, referencing and Data Calculations }\end{array}$} & \\
\hline 2. & $\begin{array}{l}\text { Fahem Ahmad Usmanii } \\
\text { (2nd Author) }\end{array}$ & & \\
\hline 3. & $\begin{array}{l}\text { Adnan Khalid } \\
\text { (3rd Author) }\end{array}$ & & \\
\hline 4. & $\begin{array}{l}\text { Tariq Salahuddin } \\
\text { (4th Author) }\end{array}$ & & Panal otn \\
\hline 5. & $\begin{array}{l}\text { Jamal Nasir } \\
\text { (5th Author) }\end{array}$ & & \\
\hline
\end{tabular}

Date of Submission: 05-07-2019

Date of Revision: 18-08-2019

Date of Online Publishing: 25-09-2019

Date of Print: 30-09-2019 